\title{
Determination of Anti-Dandruff and Hair Growth Promoting Activity of combined coconut oil extract of Marking Nut
}

\author{
Parijatha Bandigari ${ }^{1 *}$, Dr. Ashok Dongamanti ${ }^{2}$ \\ ${ }^{1,2}$ University college of Technology, Department of Chemistry, Osmania University, \\ Hyderabad, Telangana, INDIA - 500088.
}

*Corresponding Author E-mail: parijatha.pharmacy@gmail.com

\begin{abstract}
:
Dandruff, a most common dermatological disorder, is an unpleasant, chronic and pruritic scalp condition which may leads to hair loss also. This study attempted to know the activity of an herbal formulation against a dandruff causing organism Malassezia furfur which was cultured and identified from human dandruff sample and also performed the hair growth activity. Marking nuts were extracted with coconut oil and its anti-malassezial activity was evaluated based on diffusion dependent assays. Extract showed effective results comparable to a standard drug. In vivo hair growth stimulating activity for the extract was tested on denuded dorsal skin of 5-week old mice against the controls and the standard drug minoxidil. The parameters used to evaluate hair growth were hair growth completion time, hair length, hair weight, and hair follicle length and hair density. The present results provides insights on the use of Marking nuts extract for antimalassezial activity and hair rejuvenation in traditional practices.
\end{abstract}

Keywords: Marking nut, and Anti-dandruff, hair promoting activity.

\section{Introduction}

Dandruff is a common problem for the most of the people in the world. Dandruff sufferers usually complain because the scalp becomes more oily, hair becomes brittle and falls out [1]. There are various possible causes, including seborrheic dermatitis, allergic reactions, psoriasis, and eczema. Seborrheic dermatitis is the condition mainly caused by the reaction of the fungi Malassezia on the scalp [2]. Poor hygiene is not a condition, other factors like person's age, stress levels, medical conditions, and also hair products may cause dandruff. It may be more visible if a person does not wash or brush their hair frequently.

Alopecia is a Universal problem, it affects both genders. The drug of plant origin is necessary to replace the synthetic one to overcome their adverse effects. India is a repository of medicinal plants. Many of the herbs are using for preparation of various cosmetics but there were limit in use because of the lack of sound scientific backing and information [3]

\section{Complications}

Complications can sometimes result from treatment with the other drugs. Dandruff is treated by many antifungal drugs are available. The synthetic active substances include ketoconazole, zinc 
pyrithione, selenium sulfide and salicylic acid, where many of them are used to control the abundance of fungi in scalp [4]. But problems like development of fungal resistance to antibiotics, reduced efficiency and increased toxicity of synthetic drugs, are now creating the need for an alternative way of treatment. By the way, ethno botanical research gained more interest and phytoactive constituents of plants are nw some effective approach to deal antimicrobialresistance. Minoxidil is a vasodilator drug used for the treatment of alopecia. To replace the synthetic one the drug of plant origin is necessary.

\section{Material and Methods}

\subsection{Isolation and Identification of Dandruff causing Fungi}

\subsubsection{Sample Collection and Culture}

By partitioning with a sterile comb and scrapping using a sterile blunt scalpel, flakes shedding from scalp of a volunteer were collected. The specimen was then inoculated to Potato Dextrose Broth and observed for growth by incubating at $25^{\circ} \mathrm{C}$ for 48 hours. Later it was stored at $2-8^{\circ} \mathrm{C}$ for further use. The fungi broth culture was introduced to a Potato Dextrose Agar (PDA) plate, incubated at $25^{\circ} \mathrm{C}$ for 48 hours to observe colony characters. PDA plates were prepared by adding $10 \%$ tartaric acid to maintain the $\mathrm{pH}$ at 3.5 , to inhibit bacterial growth.

\subsection{Preparation of Plant extract}

\subsubsection{Collection of plant materials}

Dried nuts of Semecarpus Anacardium Linn., were collected from the local market at Hyderabad, Telangana, India. The fruits were authenticated by department of Botany Osmania University, Hyderabad.

\subsubsection{Sample selection}

The dried nuts were mixed thoroughly and sample was selected randomly

\subsubsection{Purification of Plant material}

The selected nuts were taken and cleaned by using cotton cloth. Seeds contains corrosive property so which were soaked in milk for overnight, then after removed from milk and dried under sun light. Completely dried nut were used for extraction.

\subsubsection{Extraction of plant material}

Dried seeds were grounded and taken in a beaker and boiled with coconut oil for 30 mins. Then the extract was filtered, the supernatant was used to check the activity.

\subsubsection{Preliminary Phytochemical Analysis}

For the Preliminary Phytochemical screening [5].the extract was tested for carbohydrates, alkaloids, glycosides, sterols, phenolic compounds, tannins, Flavonoids, Saponins, proteins and amino acids by using standard procedure [6].

\subsection{Determination of anti-dandruff activity}

Anti-dandruff activity was tested by disc diffusion and agar well diffusion methods; the diffusion dependent activity of the extract was evaluated based on Zone of Inhibition (ZOI).

\subsubsection{Disc diffusion method}

Hot air sterilized Whatman Filter paper discs of $6 \mathrm{~mm}$ diameter was loaded with extract of various diluted concentrations $(50 \mathrm{mg} / \mathrm{ml}, 100 \mathrm{mg} / \mathrm{ml}$ and $150 \mathrm{mg} / \mathrm{ml})$ respectively. Ketoconazole $(30 \mu \mathrm{l})$ was also 
loaded to disc and used as test standard. Standardized fungal test suspension was inoculated and uniformly spread on a PDA plate by a cotton swab. Using sterile forceps, the discs containing standard and extract of varied concentrations were laid over the surface of theagar plate; incubated at $25^{\circ} \mathrm{C}$ for 48 hours and observed.

\subsubsection{Agar well diffusion Method}

About 20-25 ml of potato dextrose agar medium for each Petriplate cooled to $45{ }^{0} \mathrm{C}$ and was added to pre sterilized plates $(150 \mathrm{~mm}$ in size). After this, Old cultures of fungal strain was spreaded over the agar plates. Petri plates were allowed to dry. About four wells in each plate of $10 \mathrm{~mm}$ diameter was punched in agar surface with the help of sterilized cork borer for sphere for placing the extracts into the well. Standard and, extract of various diluted concentrations $(50 \mathrm{mg} / \mathrm{ml}, 100 \mathrm{mg} / \mathrm{ml}$ and $150 \mathrm{mg} / \mathrm{ml})$ were loaded into the wells and incubated. The plates were kept for incubation at $30^{\circ} \mathrm{C}$ for about 48 to 72 hours. Zone of inhibition was clearly visible after 72 hours of incubation and the diameter of the zone was measured.

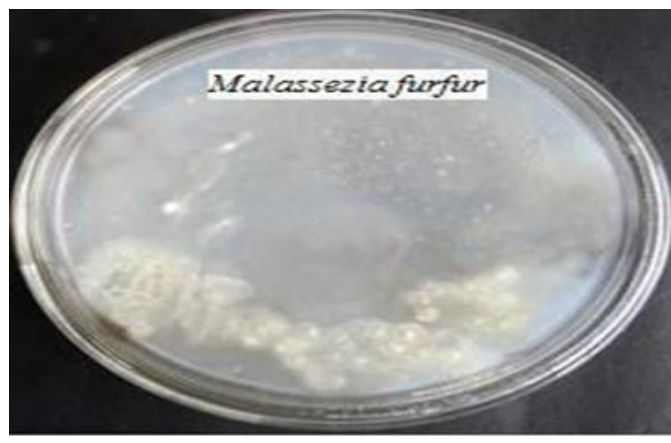

Fig. 1: Growth of Malassezia furfur against M.furfur.

Fig. 2: Antidandruff activity of semecarpus

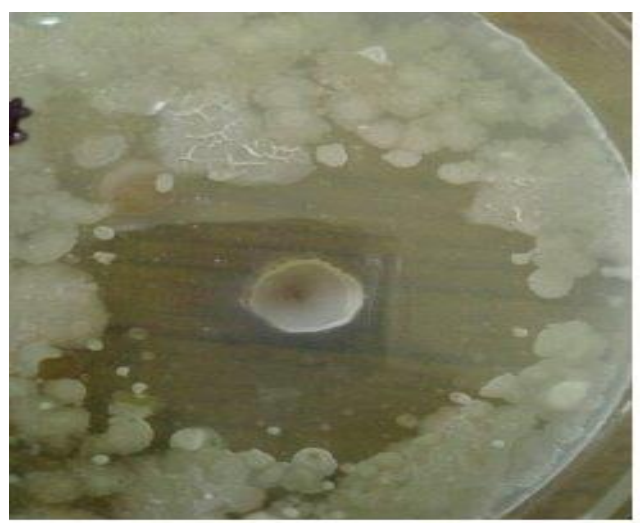

Fig. 3: Antidandruff activity of Ketoconazole against M.furfur.

\subsection{In-vivo Determination of Hair Growth Promoting activity:}

\subsubsection{Experimental animals.}

Experimental studies of Marking nuts extract was studied by using Thirty animals in 5 randomized groups The selected Five-week-old male C57BL/6 mice were allowed to adapt to their new environment for one week, with food and water provided under room temperature, $50 \pm 5 \%$ relative humidity and $12 \mathrm{hrs}$ of a light/dark cycle before the experiment was begun. The dorsal area $(2 \mathrm{~cm} \times 4 \mathrm{~cm})$ of the 6 -week-old mice was shaved with an animal clipper. After removing of hair the mice all of the hair follicles were synchronized in the telogen stage. All 
animals were randomized into 4 groups based on different topical applications: coconut oil (CO), Marking nuts extract (ME) minoxidil (MXD), and Marking nut and coconut oil combined extract (MECO). Once a day, 6 days a week, for 4 weeks (100 $\mu$ l) of each compound was topically applied to the shaved dorsal area of the mice.

\subsubsection{Quantitative hair growth study}

The method reported was followed for the quantitative evaluation of treatment. Two mice from each group were euthanized after 10 days, 20 days, and 30 days of treatment: Skin biopsies were taken from shaved area, and the specimen was preserved in $10 \%$ formalin. Tissues were placed in paraffin wax and stained with hematoxylin and eosin. Sections from all the groups were evaluate for the number of hair follicles per $\mathrm{mm}$ area of skin and percentage ratio of hair follicles in different cyclic phases, such as anagen (growth phase), catagen, and telogen (resting phase), was determined microscopically [7].

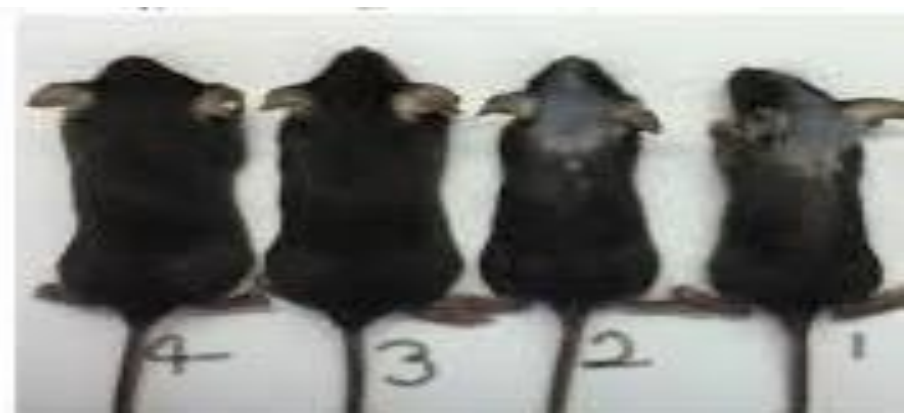

Figure 4: Hair growth-promoting effects of the extract.(1) control consisting of coconut oil only, (2) consisting of Marking nut extract only, (3) experiment consisting of coconut oil extract of marking nut (4) experiment consisting of standard dug Minoxidil after 21 days treatment.

\subsubsection{Hair length}

With the help of electric clipper hair was plucked randomly from the depilated area and measured the hair length by with the help vernier caliper Or Scale and calculated the mean of hair length [8].

\subsubsection{Hair density}

From the desired depilated area, hair was trimmed and the hair was count manually [9].

\subsubsection{Determination of Hair Weight.}

After 21 days of treatments Hair weight measurements were done. Mice were killed by physical dislocation and a from the previously shaved skin region a one square centimeter portion was cut. Skin weight with and without hair was determined, the differences in weight was recorded as the net weight of the new regrown hair.

\section{Results and Discussion}

\subsection{Preliminary Phytochemical Observation}

Preliminary Phytochemical screening, the extract was tested for carbohydrates, alkaloids, glycosides, sterols, phenolic compounds, tannins, flavonoids, Saponins and amino acids using standard procedure [10]. 
Table.1: Preliminary Phytochemical Observation

\begin{tabular}{|l|l|l|}
\hline S.No & Phytochemical Analysis & Observation \\
\hline & Alkaloids & - \\
\hline & Carbohydrates & + \\
\hline & Steroids & + \\
\hline & Phenols & + \\
\hline & Tannins & - \\
\hline & Flavonoids & - \\
\hline & Glycosides & - \\
\hline & Saponins & - \\
\hline & Terpenes & + \\
\hline
\end{tabular}

Key $(+)=$ Presence, $(-)=$ Absence

\subsection{Qualitative Studies on Anti-dandruff activity}

Table.2: Dose response and MIC of the extract.

\begin{tabular}{|l|l|l|l|}
\hline Sample & Concentration(mg/ml) & $\begin{array}{l}\text { Extract-Disc } \\
\text { Diffusion }\end{array}$ & Agar Well Diffusion \\
\hline Extract & 50 & $13.66 \pm 0.47$ & $15.33 \pm 1.24$ \\
\hline Extract & 100 & $20.83 \pm 0.62$ & $21.16 \pm 0.62$ \\
\hline Extract & 150 & $29.83 \pm 0.23$ & $29.33 \pm 0.47$ \\
\hline Standard & 30 & $31.16 \pm 1.02$ & $29.16 \pm 0.84$ \\
\hline
\end{tabular}

The combined extract exhibited a potential activity against the fungi $\mathrm{M}$. furfur. With the standard the ZOI was compared and represented intable 2. The ZOI showed by extract on disc diffusion was $13.66 \pm 0.47,20.83 \pm 0.62$ and $29.83 \pm 0.23 \mathrm{~mm}$ at 50,100 and $150 \mathrm{mg} / \mathrm{ml}$ concentrations, respectively. The extract onagar well diffusion exerted a ZOI of $15.33 \pm 1.24,21.16 \pm 0.62$ and $29.33 \pm 0.47 \mathrm{~mm}$ at 50,100 and $150 \mathrm{mg} / \mathrm{ml}$ concentrations respectively. ZOI of $31.16 \pm 1.02$ and $29.16 \pm 0.84 \mathrm{~mm}$ exhibited the standard solution at $30 \mu \mathrm{l}$ concentration. Despite differences in the phytochemical constituents the combined extract in both disc and agar well diffusion methods the ZOI was similarly expressed. With increased concentration, the ZOI range increasedand it was comparable to that of the standard used. Few patients using ketoconazole suffer dryness and itching. Such problems can be avoided by herbal alternatives procedure [11]. 


\subsubsection{Qualitative Studies on Hair Growth}

For qualitative hair rejuvenation studies parameters used were minimum time taken before visible hair growth on the shaven skin and the minimum time taken to completely grow new hair on the denude skin.

\subsubsection{Determination of Hair Length.}

Randomly selected 20 hairs were pulled and measured the length and the result noted as the mean length \pm standard deviation (SD) of 20 hairs. At time intervals of 614 and 21 days of treatment Length measurements were done.

\section{Table of Results}

Table 3: Effect of different hair formulation on hair length in $\mathbf{m m}$ of mice in hair growth activity

\begin{tabular}{|l|l|l|l|}
\hline S.NO & $\begin{array}{c}\text { Animal } \\
\text { Groups }\end{array}$ & Formulation type & $\begin{array}{l}\text { Length of hair in } \\
\mathbf{m m}(\mathbf{m e a n} \pm \text { SD) }\end{array}$ \\
\hline $\mathbf{1}$ & Group 1 & Vehicle Coconut oil(CO) & $2.10 \pm 0.087$ \\
\hline $\mathbf{2}$ & Group 2 & Minoxidil 2\% solution(MXD) & $5.09 \pm 0.348$ \\
\hline $\mathbf{3}$ & Group 3 & Marking nuts extract(ME) & $3.88 \pm 0.155$ \\
\hline $\mathbf{4}$ & Group 4 & $\begin{array}{l}\text { Marking nut and coconut oil } \\
\text { combined extract (MECO). }\end{array}$ & $4.15 \pm 0.354$ \\
\hline
\end{tabular}

Table 4: Effect on hair density of different hair formulation

\begin{tabular}{|l|l|l|l|}
\hline S.NO & Groups & Drug Formulation & Hair density (mean \pm SD) \\
\hline $\mathbf{1}$ & Group 1 & Vehicle Coconut oil(CO) & $1195 \pm 37.25$ \\
\hline $\mathbf{2}$ & Group 2 & Minoxidil 2\% solution(MXD) & $2529 \pm 35.69$ \\
\hline $\mathbf{3}$ & Group 3 & Marking nuts extract(ME) & $1676 \pm 26.59$ \\
\hline $\mathbf{4}$ & Group 4 & $\begin{array}{l}\text { Marking nut and coconut oil combined } \\
\text { extract (MECO). }\end{array}$ & $2657 \pm 39.85$ \\
\hline
\end{tabular}

Table 5: Effect of different hair formulation on hair weight in mg of mice in hair growth activity

\begin{tabular}{|l|l|l|l|}
\hline S.NO & Groups & Drug Formulation & Hair density (mean \pm SD) \\
\hline $\mathbf{1}$ & Group 1 & Vehicle Coconut oil(CO) & $36.61 \pm 1.30 \mathrm{mg}$, \\
\hline $\mathbf{2}$ & Group 2 & Minoxidil 2\% solution(MXD) & $51.81 \pm 1.36 \mathrm{mg}$ \\
\hline $\mathbf{3}$ & Group 3 & Marking nuts extract(ME) & $45.81 \pm 1.36 \mathrm{mg}$ \\
\hline $\mathbf{4}$ & Group 4 & $\begin{array}{l}\text { Marking nut and coconut oil combined } \\
\text { extract (MECO). }\end{array}$ & $53.34 \pm 1.72 \mathrm{mg}$ \\
\hline
\end{tabular}




\subsubsection{Hair length}

Table1, In Group-1, Group-2, Group-3 and Group-4, represents hair growth activity, the hair length of all groups shown were found to be $2.24,5.55,3.93 \mathrm{~mm}$ and $3.89 \mathrm{~mm}$, respectively [12].

\subsubsection{Hair density}

Table 2. In Group-1, Group-2, Group-3 and Group-4, represents hair density, it was found to be $1195,2529,1676$ and 2657 , per $\mathrm{cm} 2$, respectively

\subsubsection{Determination of Hair Weight.}

Mice were treated with the CO, MXD, ME and MECO extracts had hair weight of $36.61 \pm$ $1.30 \mathrm{mg}, 51.81 \pm 1.36 \mathrm{mg}, 45.81 \pm 1.36 \mathrm{mg}$ and $53.34 \pm 1.72 \mathrm{mg}$ respectively.

\subsubsection{Toxicity Studies.}

Although marking nuts seeds are a common relish, investigations to determine the toxicity on mice were done before the experiment commenced [13].

\section{CONCLUSION}

Crude herbal drugs have been included in traditional medicine and household remedies for a long time. This study revealed the effectiveness of Marking nuts seeds and coconut oil combined extract for the management of dandruff and Hair growth promoting activity this kind would help to combat problems like antimicrobial resistance and other irritant properties of drugs. In vitro evaluation proved its appreciable diffusion dependent Zone of Inhibition against M. furfur and In-vivo activity determines the good hair promoting activity.

\section{ACKNOWLEDGEMENTS}

One of the authors Dr. D. Ashok is thankful to UGC, New Delhi for the award of UGC-BSR faculty fellowship [Sanction No. F. 18- 1/2011(BSR)/2018].

\section{References}

1. Arora P., Nanda A and Karan M "Plants used in management of Dandruff". The Indian Pharmacist. March, 2011pg: 28-31.

2. Singla chhavi, Drabu sushma, Ali Mohammad "Potential of herbals as antidandruff agents". International Research journal of Pharmacy. 2: 3, 2011 pg: 16-18.

3. Vijayakumar R., C. Muthukumar, T. Kumar, R. Saravanamuthu (2006) "Characterization of Malassezia furfur and its control by using plant extracts". Indian Journal of Dematology. vol 51 2, 2006 145-148.

4. Lee, Jeong-Hyun and Jae-Sug Lee. "Chemical composition and Antifungal Activity of Plant Essential Oils against Malassezia furfur” Kor. J. Microbiol. Biotechnol. 38: 3, 2010 315-321.

5. Arora pooja, Nanda Arun, Karan Mahinder "Screening of plant essential oils for antifungal activity against malassezia furfur" Int.journal of pharmacy \& pharmaceutical sciences. Vol.5, issue2,2013, 37-39

6. Abhijeet pandey, Jui V. Jagpat, S. A. Polshettiwar. "Formulation and Evaluation of in-vitro Antimicrobial activity of gel containing essential oils and effect of polymer on their 
antimicrobial activity" International Journal of Pharmacy and Pharmaceutical Sciences. vol 3: 1,2011, pg: 234-237.

7. Stough D., Stenn K., Haber R., Parsley W.M., Vogel J.E., Whiting D.A., Washenik K. Psychological effect, pathophysiology, and management of androgenetic alopecia in men. Mayo Clin. Proc. (2005); 80:1316-1322.

8. Shapiro J., Price V.H. Hair regrowth therapeutic agents. Dermatol. Clin. (1998); 16:341-356.

9. Buhl A.E., Waldon D.J., Baker C.A., Johnson G.A. Minoxidil sulfate is the active metabolite that stimulates hair follicles. J. Invest. Dermatol. (1990); 95:553-557.

10. Messenger A.G., Rundegren J. Minoxidil: mechanisms of action on hair growth. Br. J. Dermatol. (2004); 150:186-194.

11. Inoue T., Sugimoto Y., Masuda H., Kamei C. Effect of peppermint (Mentha piperita L.) extracts on experimental allergic rhinitis in rats. Biol. Pharm. Bull. (2001); 24:92-95. doi: $10.1248 / \mathrm{bpb} .24 .92$

12. Schelz Z., Molnar J., Hohmann J. Antimicrobial and antiplasmid activities of essential oils. Fitoerapia. (2006); 77:279-285.

13. Han J.H., Kwon O.S., Chung J.H., Cho K.H., Eun H.C., Kim K.H. Effect of minoxidil on proliferation and apoptosis in dermal papilla cells of human hair follicle. J. Dermatol Sci. (2004); 34:91-98. 